\title{
APOIO COMO MEDIDA TERAPEUTICA NO RELACIONAMENTO ENFERMEIRA-PACIENTE
}

\author{
Maguida Costa Stefanelli* \\ Evalda Cançado Arantes** \\ Ilza Marlene Kuae Fukuda*
}

STEFANELLI, M. C.; ARANTES, E. C.; FUKUDA, I. M. K. Apoio como medida terapêutica no relacionamento enfermeira-paciente. Rev. Esc. Enf. USP, São Paulo, 15 (1) :43-48, 1981 .

As autoras apresentam algumas considerações teóricas sobre o apoio. Consideram-no uma das mais eficazes medidas terapêticas que a enfermeira pode utilizar no seu relacionamento com o paciente. Relatam a aplicação do apoio num processo de relacionamento terapêutico aluna-paciente.

\section{INTRODUÇÃO}

O relacionamento terapêutico enfermeira-paciente como a expressão diz, é função específica da enfermeira e não dos demais membros da equipe de enfermagem como destaca TRAVELBEE ${ }^{3}$, é uma meta a ser atingida. Para que a aluna de enfermagem possa desempenhar esta função, quando na vida profissional, na disciplina Enfermagem Psiquiátrica desta Escola ela tem oportunidade de vivenclaro processo de relacionamento terapêutico.

Nesta experiência ela aplica os conhecimentos teóricos adquiridos e pode perceber características, problemas, fenômenos e fases inerentes ao processo. Em sua atuação vale-se da comunicação verbal e não verbal na aplicação de medidas terapêuticas, ao tentar ajudar o paciente. Entre essas medidas temos oferecimento de apoio, estabelecimento de limites, ajuda na expressão de sentimentos e uso de técnicas terapêuticas de comunicação.

$\mathrm{O}$ apoio é considerado uma das medidas terapêuticas mais eficazes no processo de relacionamento terapêutico.

Desde que o aluno começa a interagir com pacientes, passa a familiarizar-se com a palavra apoio. Naturalmente inseguro pela sua inexperiência, o aluno não sabe como oferecer este apoio, do qual ele muitas vezes tanto necessita em face de situações novas.

Não é fácil conceituar apoio. CARTER ${ }^{1}$ relata que, ao solicitar às enfermeiras norte-americanas uma definição de apoio, obteve delas a resposta de que apoio é algo difícil de ser definido ou que não pode ser ensinado nem aprendido.

Nós, porém, acreditamos que todo profissional da área da saúde, desde que devidamente orientado, é capaz de usar técnicas terapêuticas para oferecer apoio. Apesar de concordarmos com a dificuldade na definição de apoio estamos conscientes de que ele é essencial no relacionamento terapêutico enfermeira-paciente.

\footnotetext{
* Professor Assistente da disciplina Enfermagem Psiquiátrica da EEUSP. Mestre em Enfermagem. * * Professor Assistente Doutor da disciplina Enfermagem Psiquiátrica da EEUSP.
} 
A definição operacional de apoio, oferecida por CARTER ${ }^{1}$, parece-nos a mais adequada à interação enfermeira-paciente:

- uma pessoa percebe na outra uma necessidade não-satisfeita e esta percepção pode estar ou não correta;

- há um aumento no nível de ansiedade de uma ou de ambas as pessoas envolvidas na situação;

- este aumento da ansiedade é percebido por meio do sentimento empático;

- uma das pessoas faz tentativa para diminuir a ansiedade da outra; e

- se a tentativa for bem sucedida ambas experimentam diminuição em seu nível de ansiedade, porém, se falhar a tentativa, o nível de ansiedade de ambas tende a aumentar, o que poderá provocar uma situação de pânico.

$\mathrm{Na}$ tentativa de descobrir as necessidades do paciente, a enfermeira precisa acautelar-se para que as suas próprias necessidades não-salisfeitas não venham eclipsar as necessidades do outro. Depreende-se, então, a importância da enfermeira conhecer suas próprias necessidades não-satisfeitas para evitar que estas influenciem seu relacionamento com o paciente.

Para diminuir a ansiedade do paciente a enfermeira pode lançar mão do apoio, usando os diversos recursos já conhecidos. Na situação do dia-a-dia com o paciente, ela poderá descobrir novas técnicas para oferecer apoio, de acordo com a peculiaridade de cada paciente.

HOFLING et alii $^{2}$ apresentam de forma didática as técnicas que a enfermcira pode utilizar para oferecer apoio:

- permanecer ao lado do paciente em momentos de tensão emocional e quando demonstra estar perturbado e incapaz de ver os fatos com clareza;

- ajudar o paciente a tomar decisões e a reconhecer suas próprias limitações;

- tentar ser sensivel aos sentimentos e às necessidades do paciente;

- planejar com o paciente suas experiências construtivas, atendendo a seus interesses sempre que possivel;

- ajudar o paciente a ressaltar suas características sadias, a perceber seus progressos e sucessos e a valorizá-los;

- oferecer ao paciente ambiente seguro para que ele teste suas habilidades, sem prejuízo para si próprio e para os demais que o cercam; e

- saber ouví-lo.

O saber ouvir, técnica de comunicação terapêutica, é um recurso eficaz que a enfermeira pode usar para oferecer apoio ao paciente.

$O$ saber ouvir no relacionamento terapêutico enfermeira-paciente requer dela esforço de concentração, disponibilidade de tempo para dedicar a ele e reflexão profunda para tentar entender o significado da mensagem que o paciente transmite.

Ouvir de modo reflexivo corresponde, na linguagem escrita, ao que comumente se considera ler nas entrelinhas. Ao ouvir reflexivamente a enfermeira tem 
que estar atenla para captar as mensagens que o paciente transmite por meio da comunicação não verbal. Esta nem sempre é coerente com o que o paciente expressa verbalmente e, às vezes, contém mensagens mais significativas que aquela.

No trabalho de WILSON ${ }^{4}$ encontra-se uma análise do conceito de saber ouvir que poderá ajudar a enfermeira a se desenvolver na tarefa de ouvir reflexivamente. A autora destaca como fases do "ouvir" aspectos que devem ser considerados: propósito, emoção, atenção, compreensão, avaliação, resposta e satisfação que para a uutora se constitui no objetivo final da interação.

\section{RELATO DE UMA EXPERIENCIA}

Uma aluna desenvolveu o processo de relacionamento terapêutico com a paciente $P$ internada em uma unidade psiquiátrica. Seu comportamento era caracterizado por sintomas de alheamento da realidade. No relacionamento aluna-paciente a medida terapêutica predominantemente usada foi oferecimento de apoio.

$P$ era casada e tinha dois filhos, estando o mais novo com 8 meses de idade. As mudanças de comportamento que motivaram sua internação começaram a manifestar-se após o nascimento do segundo filho.

Resumidamente, o comportamento da paciente, no início do processo do relacionamento terapêutico enfermeira-paciente, pode scr assim descrito: ficava a maior parte do tempo em seu quarto, na cama, ora deitada em decúbito dorsal, imóvel, com as pálpebras fechadas ora sentada na beira da cama, curvada para frente, imóvel e com as mãos apoiadas nos joelhos. Quando ia tomar banho tirava suas vestes, ficava sob o chuveiro durante um minuto e saía rapidamente. Quando permanecia com os olhos abertos, parecia nada perceber a sua volta. Não conversava com as companheiras de enfermaria nem com outras pessoas da unidade. Não respondia aos estímulos, permanecia calada o tempo todo. Quando andava mantinha os braços flexionados com as mãos na altura do abdome; raramente respondia às solicitações e quando o fazia era apenas um aceno de cabeça ou com monossílabos quase inaudiveis; não fazia o que lhe era sugerido, não participava de atividades inidviduais ou de grupo, mesmo quando para isso era estimulada; parecia não se interessar por coisa alguma; quando alguém a tocava com as mãos dava a impressão de querer desvencilhar-se, tentando, aparentemente, evitar qualquer contato com outras pessoas; se alguém permanecia a seu lado, mudava constantemente de posição - sentava-se na cama, deitava-se a seguir levantava-se, passava as mãos nos cabelos e, às vezes, debruçava-se sobre a cama de outra paciente; sua expressão facial nestes momentos denotava ora tristeza, ora indiferença; às vezes, quando a aluna se aproximava, esboçava expressão de choro, movia os lábios, mas não emitia sons; recusava-se a tomar medicamentos por via intramuscular e os que lhe eram ministrados por via oral eram ingeridos de uma só vez, em movimento brusco; quando chegava o carro com alimentos e as funcionárias chamavam a pacientes para tomar a refeição, $\mathbf{P}$ levantava-se, ia até a porta, tornava a sentar-se ou permanecia parada na porta, oscilando seu corpo ora para frente, ora para trás; só se dirigia para o refeitório quando alguém a levava; ingeria os alimentos rapidamente sem mastigá-los e repetia a porção servida; saía do refeitório antes das outras pacientes, parecendo ignorar a rotina que exigia a permanência no refeitório até que todas terminassem de comer. 
À noite, permanecia no leito, de pálpebras cerradas, parecendo dormir.

Foi com esse comportamento que a aluna encontrou a paciente e decidiu firmar o compromisso de ajuda. Foram realizadas nove entrevistas formais e seis informais. Estas últimas foram levadas a efeito quando houve, por parte da paciente, recusa em participar da entrevista formal.

A primeira entrevista teve duração de dez minutos. A aluna apresentou-se, disse qual era sua função, de onde era, quais eram seus objetivos, os dias e horário que estaria à disposição da paciente. Falou ainda sobre a anotação da interação e sua finalidade.

Enquanto a aluna falava a paciente permanecia andando pela enfermaria, sem lhe dirigir o olhar. De repente parou e segurou bruscamente a mão da aluna.

A aluna experimentou ansiedade em nível crescente em face do comportamento de $\mathrm{P}$. Solicitou à professora uma conferência de supervisão. Nesta foi dada toda oportunidade à aluna para verbalizar seus sentimentos e a seguir foi discutida a melhor conduta a ser seguida; a aluna disse estar desorientada e não compreendeu o porquê do comportamento da paciente. Após discussão ela concluiu que deveria estudar mais as formas de oferecer apoio para tentar aplicá-las de modo individualizado. Antes de qualquer outra atividade a aluna foi orientada a permanecer ao lado da paciente, durante o periodo de tempo em que conseguisse controlar sua ansiedade. Esta ansiedade não deveria ser percebida pela paciente.

$\mathrm{Na}$ segunda entrevista a ansiedade da aluna aumentou pois, além de $\mathrm{P}$ não responder às suas solicitações, virava-lhe as costas, bocejava, às vezes descerrava as pálpebras, parecendo estar verificando se ela ainda estava lá. Esta sentiu-se mais desorientada, rejeitada e irritada por perceber estar sendo testada pela paciente.

Após esta entrevista, com uma carga emocional muito intensa, a aluna solicitou nova conferência de supervisão. Disse que nada conseguira fazer por $\mathbf{P}$; que tudo quanto tentara fora inútil. Após análise do comportamento da paciente e avaliação do que este causava na aluna, esta resolveu aceitar o desafio para manter relacionamento de ajuda com P. Além de tudo, achou injusto escolher outra paciente para desenvolver o processo de relacionamento terapêutico, porque $P$ era a que mais necessitava de ajuda naquele momento.

A partir dessa conferência de supervisão, é que a aluna percebeu sua aceitação do compromisso de ajuda.

A duração das entrevistas foi aumentando gradativamente, de dez minutos na fase inicial para sessenta na fase final. Ela conseguiu desenvolver a habilidade em tolerar o silêncio de modo terapêutico.

A aluna afirmava que enquanto permanecia ao lado da paciente indagava frequentemente a si própria: $O$ que fazer para ajudar a paciente? $O$ que poderia levá-la a falar novamente? Por que estaria sofrendo tanto? Como descobrir seus interesses?

Várias vezes a aluna tentou abordar $P$, falando sobre seus filhos, mostrandolhe gravuras que continham crianças ou, então, por meio de perguntas diretas. Não obteve qualquer resposta verbal mas percebeu que a ansiedade da paciente 
aumentava nestes momentos porque apresentava tremores nas mãos, levantava-se e passava as mãos nos cabelos.

Após esta entrevista foi feita nova conferência de supervisão. A aluna havia estudado novamente o apoio e as técnicas de comunicação terapêutica. Após discutir com a professora estes assuntos concluiu que deveria ficar ao lado de $\mathbf{P}$ o maior tempo possivel, além do tempo destinado à entrevista formal, acompanhando-a em suas atividades diárias, sem ser insistente. Tentava demonstrar à paciente que era sensivel aos seus sentimentos e procurava descobrir seus novos interesses.

A aluna passou a permanecer ao lado de $P$, verbalizando sua disponibilidade e interesse em ajudá-la. Auxiliava-a a decidir a tomar banho, a tomar café, a dirigir-se à fila do almiço; lembrava-o a ir ao sanitário para satisfação de suas necessidades fisiológicas. Aproveitava enfim todas as oportunidades para lembrar a $\mathbf{P}$ que estava presente e que tinha interesse genuíno na sua pessoa.

Por ocasião da quinta entrevista, após 25 dias do inicio do relacionamento, $\mathbf{P}$ ainda não respondia verbalmente à aluna, mas já a encarava e atendia a algumas de suas solicitações. A aluna aproveitou para relembrar à paciente alguns aspectos do contrato firmado no início do relacionamento como seus objetivos, horário préestabelecido para as entrevistas e privacidade das mesmas. A seguir, $\mathbf{P}$, que parecia não ouvir o que a aluna estava dizendo, segurou a mão desta com firmeza, por aproximadamente um minuto, como se estivesse pedindo ajuda.

Na sexta entrevista, permitiu que a aluna aparasse as unhas de uma de suas mãos. Nesta ocasião $\mathbf{P}$ já não dava as costas à aluna, olhava para ela por alguns momentos, às vezes esboçava um sorriso e, uma vez, segurou fortemente o braço da aluna e chorou por aproximadamente cinco minutos. A aluna permaneceu em silêncio ao seu lado, tentando controlar a própria ansiedade que era intensa pois, nesta época, já experimentava sentimento empático e envolvimento emocional com $P$, porém consciente e em níveis terapêuticos.

Depois de 29 dias do início do relacionamento terapêtico foi prescrita, eletroconvulsoterapia para P. A aluna preparou-a para o tratamento. No dia da primeira aplicação $\mathbf{P}$ não queria deitar-se. A aluna abordou-a, lembrou-lhe a necessidade de ficar deitada e disse-lhe que permaneceria a scu lado. $\mathrm{P}$ deitou-se imediatamente. Quando despertou, após o tratamento, estava tranqüila, porém, parecia procurar alguém com o olhar. Ao ver a aluna sorriu e repousou novamente.

Na conferência de supervisão a aluna foi orientada a tentar aproveitar esta aceitação aparente de sua pessoa, oferecendo-lhe todas as oportunidades que a unidade de internação propiciava aos pacientes, na tentativa de descobrir algum interesse de $\mathbf{P}$. A aluna ficou muito surpresa quando $\mathbf{P}$ começou a jogar damas com ela e a ganhar. A aluna sentiu gratificação de seus esforços que foi ainda maior porque $\mathbf{P}$ a defendeu quando outra paciente a criticou por estar perdendo. $\mathbf{P}$ disse: "É porque ela não sabe jogar ainda".

O fato da paciente ter saído de seu mutismo deixou a aluna tão emocionada que precisou retirar-se por uns minutos para controlar a sua emoção; voltou a jogar com $P$ que continuou falando sobre as regras do jogo em voz audível e com linguagem clara. 
A aluna foi orientada pela professora a continuar ao lado da paciente e a estimular, gradativamente, sua expressão de sentimentos.

A primeira pessoa com quem a paciente falou foi a aluna. Recusava-se a conversar com seu médico. Este só podia orientar o tratamento e fazer a evolução clinica de $\mathbf{P}$ baseado nas observação e informações da aluna.

Após o jogo de damas acima referido $P$ caiu novamente em mutismo. Voltou a falar, nove dias depois, para reclamar que seus cigarros não dariam até o dia da visita. A aluna encaminhou $P$ à enfermeira e juntas programaram a divisão dos cigarros que restavam; aproveitou para lembrar à paciente que permaneceria na unidade só por mais uma semana.

Neste mesmo dia a aluna ofereceu-lhe novamente uma revista que continha gravuras de crianças. $\mathbf{P}$ folheou a revista, teceu comentários sobre as gravuras, relacionando-as com seus filhos; a seguir falou com naturalidade e propriedade sobre sua gestação e seus filhos.

$\mathrm{Na}$ nona e última entrevista formal (décima quinta entrevista) a paciente, dirigindo-se à aluna, disse: "Dona $\mathrm{A}$ tenho tantas coisas para contar à senhora e nem sei por onde começar. Tenho vergonha de tudo que se passou comigo. Eu sei que a senhora sempre tentou me ajudar, ficou a meu lado e eu não reconheci isto". A seguir relatou todas as manifestações de sua doença e conversou com o médico atendendo o pedido da aluna.

Após esses acontecimentos foi possível fazer com $P$ seus planos para o futuro em relação a ela mesma, seu filhos, sua casa, dentro de suas reais condições. A este respeito a aluna só pôde participar estimulando a paciente a planejar sua vida e solicitando à enfermeira da unidade para dar continuidade na assistência à paciente, pois era seu último dia de estágio.

Ao término do curso a aluna comentou sua mudança de atitude em relação ao doente mental e que se não tivesse vivenciado um processo de relacionamento de ajuda jamais acreditaria na ação benéfica do apoio, quando oferecido terapeuticamente.

STEFANELli, M. C.; ARANTES, E. C.; FUKUDA, I. M. K. Support as a therapeutic measure in the nurse patient relationship. Rev. Esc. Enf. USP, São Paulo, 15(1): $43-48,1981$.

The authors make some theoretical considerations about support. They consider it one of the most efficient measures the nurse can use in her relationships with patient. They report the application of such measure in a process of student-patient therapeutic relationships.

\section{REFERENCIAS BIBLIOGRAFICAS}

1. CARTER, E. W. Support: a lay concept in nursing. In: BURD, S. F. \& MARSHALL, M. A. Some clinical approaches to psychiatric nursing. London, Macmillan, 1970. p. 63-6.

2. HOFLING, C. K. et alii. Enfermería psiquiátrica. México, Interamericana, 1970. p. 23-60.

3. TRAVELBEE, J. Intervención en enfermería psiquiátrica. Carvajal, Cali, 1979. p. $41-58$.

4. WILSON, L. M. Listening. In: CARLSON, C. E. Behavloral concepts \& nursing intervention. Philadelphia, J. B. Lippincott, 1970. p. 153-70. 